Article

\title{
Rapid and Effective Isolation of Dissolved Organic Matter Using Solid-Phase Extraction Cartridges Packed with Amberlite XAD 8/4 Resins
}

\author{
Hojung Rho ${ }^{1}\left(\mathbb{D}\right.$, Kangmin Chon ${ }^{2}$, Jongkwan Park ${ }^{1, *}$ and Jaeweon Cho ${ }^{1, *}$ \\ 1 School of Urban and Environmental Engineering, Ulsan National Institute of Science and \\ Technology (UNIST), 50 UNIST-gil, Eonyang-eup, Ulju-gun, Ulsan 44919, Korea; hjrho2014@gmail.com \\ 2 Department of Environmental Engineering, College of Engineering, Kangwon National University, \\ 1 Kangwondaehak-gil, Chuncheon-si, Gangwon-do 24341 Korea; kmchon@gmail.com \\ * Correspondence: jkpark@unist.ac.kr (J.P.); jaeweoncho@unist.ac.kr (J.C.); \\ Tel.: +82-52-217-3060 (J.P.); +82-52-217-2833 (J.C.)
}

Received: 5 December 2018; Accepted: 22 December 2018; Published: 2 January 2019

\begin{abstract}
Using the conventional XAD 8/4 method with general columns to isolate dissolved organic matter (DOM) is extremely time-consuming and labor-intensive. This study presents a rapid and effective method using solid-phase extraction (SPE) cartridges packed with XAD 8/4 resins for isolating various DOMs. The relative fraction (percentage hydrophobic, transphilic, and hydrophilic) of the various DOMs processed by both methods showed similar values. Moreover, changes in the molecular weight distribution of effluent from XAD 8/4 resins processed by both methods showed the same ultraviolet (UV) and fluorescence absorbance pattern s. The biopolymer compositions of eluates from XAD $8 / 4$ resins also showed no significant difference between the two methods. However, higher carbon recovery of the isolation method using SPE cartridges was found (with columns: 88.9\%; with SPE: 95.9\%). In addition, the proposed method using SPE cartridges packed with XAD 8/4 resins is much faster than that using general columns (with columns: $1468 \mathrm{~min}$; with SPE: $485 \mathrm{~min}$ ). The proposed isolation method is highly efficient and accurate; it is an excellent candidate method for isolating various DOMs.
\end{abstract}

Keywords: humic acid; XAD resin; solid-phase extraction; hydrophobicity

\section{Introduction}

Recently, interest in drinking water analysis for natural organic matter (NOM), which is of health and aesthetic concern, has rapidly increased [1]. NOM, which exists in ground and surface water, consists of complex and heterogeneous compounds composed of humic substances, carbohydrates, proteins, and others at levels of parts per million [2,3]. Thus, it is necessary to isolate and concentrate dissolved organic contaminants prior to chemical analysis [4].

Although there are many well-documented resin techniques for the isolation and concentration of organic matter from water, only a few studies have been conducted to quantitatively investigate the sorption and elution of organic matter from water by various resins. In recent years, combined XAD $8 / 4$ resins have been used to isolate organic solutes from water [5-7]. The properties of XAD 8/4 resins are well understood, and extensive studies have been conducted to evaluate resin performance in the isolation and recovery of organic matters from water [8-10]. The combined isolation method for dissolved organic matter (DOM) with XAD 8/4 resins has been extensively used in water chemistry research. It has been established that the so-called hydrophobic (HPO) fraction of DOM adsorbs onto the XAD 8 resin from water samples and can then be eluted from the resin using $0.1 \mathrm{~N} \mathrm{NaOH}$ solution. Another large fraction of the DOM in water is the transphilic (TPI) fraction, which does not adsorb onto XAD 8 resin but onto XAD 4 resin. The TPI fraction can also be eluted from the XAD 4 resin using 
an $0.1 \mathrm{~N} \mathrm{NaOH}$ solution. The final fraction of the DOM is called the hydrophilic (HPI) fraction, which does not adsorb onto either XAD 8 or XAD 4 resins (Figure 1) [11].

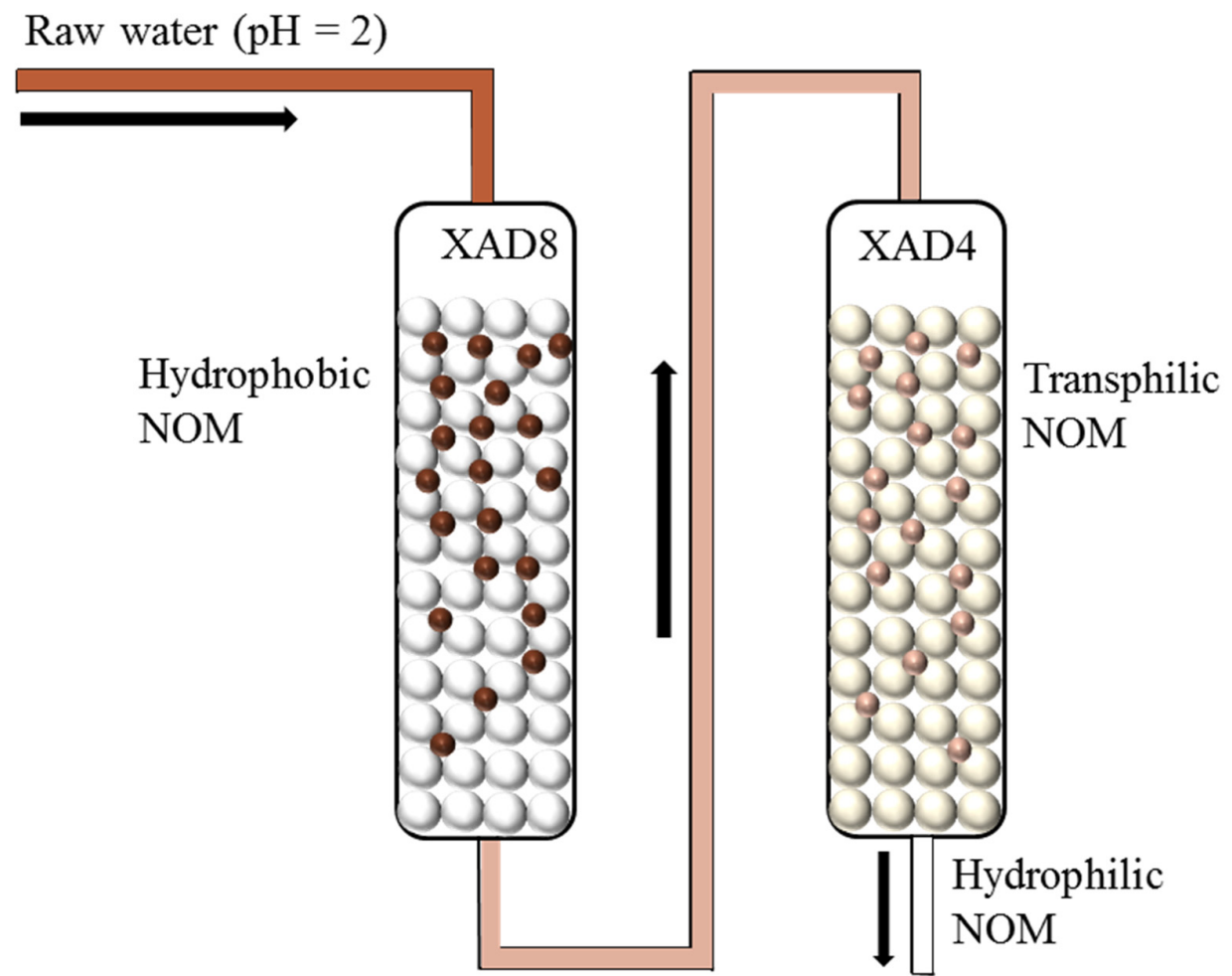

Figure 1. Schematic concept for the isolation of dissolved organic matter (DOM) using XAD 8 and XAD 4 resins.

However, the conventional combined XAD 8/4 resin method has some limitations for the effective isolation of organic matter. Glass columns equipped with peristaltic pumps and Teflon tubing were generally used for loading the water samples in combined XAD 8/4 resin systems. The tubing line must be manually reset as the cleaning solution is changed. Hence, using the conventional combined XAD 8/4 resin system can be inconvenient when large numbers of water samples are to be isolated. In addition, the carbon mass recovery of organic matter in the combined XAD 8/4 resin system can vary, as the glass columns and the tubing are manually set.

To overcome these limitations of the conventional combined XAD 8/4 resin method, a solid-phase extraction (SPE) technique was applied to develop an automated method for isolation of organic matter using cartridges filled with XAD 8/4 resins. The SPE method is widely used as a sample-preparation and a selective extraction technique for the isolation and concentration of selected water samples [12]. The water sample is transferred to an SPE cartridge, and the DOM is adsorbed into the resin in the cartridge by various interactions (e.g., HPO interaction). The isolated sample is recovered by elution using a liquid or fluid, or by thermal desorption into the gas phase. The strong advantage of an SPE method is that a high level of automation is possible using online interfaces for the isolation of DOM from water samples.

Although many studies have investigated the SPE method for isolating or concentrating a solute in many areas of chemistry, including environmental, pharmaceutical, clinical, food, and industrial chemistry [13-16], the SPE method using cartridges packed with XAD 8/4 resins has not yet been applied for the isolation of DOM. Accordingly, the purpose of this study is to validate the isolation method using an automated SPE device equipped with cartridges packed with XAD 8/4 resins to develop an effective isolation method for various kinds of organic matter. Therefore, the combined XAD 8/4 isolation method with general columns and SPE cartridges are rigorously compared in terms of relative HPO fraction, carbon mass recovery, and chemical analysis of the effluent and eluate solutions from the XAD resins. 


\section{Materials and Methods}

\subsection{Water Sample Preparation}

Aldrich humic acid (AHA) purchased from Sigma-Aldrich (St. Louis, MO, USA) was used for experiments as model organic matter. Moreover, three types of water samples (i.e., Muryeongari wetland (MW-NOM), Han River (HR-NOM), and Suwannee River NOM (SR-NOM)) were selected to investigate the difference in the efficiency of isolation of NOM using the two considered methods (with general columns and with SPE devices). MW-NOM and HR-NOM were taken from surface water in the Muryeongari wetland and Han River in Korea, respectively. Suwannee River NOM samples (SR-NOM) were purchased from the International Humic Substance Society (IHSS) (St. Paul, MN, USA). Prior to analyses, all the collected water samples were pretreated by using a $0.45-\mu \mathrm{m}$ mixed cellulose ester membrane filter (Millipore, Bedford, MA, USA) and acidified to pH 1.95 with $0.1 \mathrm{M} \mathrm{HCl}$.

\subsection{Procedure of Combined XAD 8/4 Resins Isolation with General Columns}

The isolation of DOM based on hydrophobicity generally proceeds using Amberlite XAD 8 and XAD 4 resins in series: the XAD 8 resin is used first, followed by the XAD 4 resin (Figure 1). XAD 8/4 resins were dried overnight in an oven at $70{ }^{\circ} \mathrm{C}$. The resins were left in a desiccator to reach the ambient temperature before being sieved to sizes of $0.1 \mathrm{~cm} \times 0.1 \mathrm{~cm}$ to obtain uniform size distributions. $21.5 \mathrm{~g}$ of XAD 8/4 resins were aspirated into glass columns (i.d. $=0.7 \mathrm{~cm}$, length =15 cm) to obtain 7-cm-long beds. A Gilson peristaltic pump was used for loading the water sample; it was connected to the top of the column of XAD 8 resin using Teflon tubing (i.d. $=0.8 \mathrm{~mm}$ ). The bottom of the column of XAD 8 resin was connected to the column of XAD 4 resin with Teflon tubing. The water sample was passed through the column of XAD 8 resin, and then the effluent from the column of XAD 8 resin was passed through the column of XAD 4 resin. The installed system was further cleaned repeatedly with DI (Deionized) water, $0.1 \mathrm{M} \mathrm{HCl}$, and $0.1 \mathrm{M} \mathrm{NaOH}$ to remove any impurities.

The HPO fraction of DOM was quantitatively adsorbed onto XAD 8 resin, and the TPI fraction of DOM was adsorbed onto XAD 4 resin, according to the procedure of Malcom [6,11]. $600 \mathrm{~mL}$ of samples were passed through the combined resin system (XAD 8 followed by XAD 4). The effluent from the column of XAD 8/4 resins was sampled after $200 \mathrm{~mL}$ of water samples had passed through the combined resin system (the column void volume is generally $67 \%$ of the resin bed volume [11]). After each run, the HPO and TPI fractions of DOM were back-eluted from the columns of XAD 8/4 resins using $0.1 \mathrm{M} \mathrm{NaOH}$ with the precautions mentioned in Macolm [6,11]. The eluates were immediately neutralized using $0.1 \mathrm{HCl}$ to avoid the oxidation of DOM.

Determination of a sufficient amount of resin to prevent exceeding the adsorption capacity $\left(q_{e}\right)$ is required. Column adsorption experiments for XAD 8/4 resins were conducted to evaluate the sufficient amount of resin at room temperature $\left(20^{\circ} \mathrm{C}\right)$ through a combined XAD $8 / 4$ resin method with general columns and a 600-mL solution of AHA. The dissolved organic carbon (DOC) concentrations of the AHA solution were adjusted to $10 \mathrm{mgC} \mathrm{L}^{-1}$. The $\mathrm{pH}$ of the solution collected from each column was preserved at $\mathrm{pH}$ 6.5. To obtain the breakthrough curve, the effluent from the column of XAD8/4 resins was collected every $20 \mathrm{~min}$. Column studies were terminated when the column reached exhaustion when the DOC concentration of effluent from the columns was increasing.

The adsorption capacity $q_{e}(\mathrm{mgC} / \mathrm{mg})$ was calculated using:

$$
q_{e}=\frac{V_{i} C_{i}-V_{e} C_{e}}{W}
$$

where $C_{i}$ and $C_{e}$ are the carbon concentrations of the initial and effluent solutions of AHA from the XAD 8/4 columns (mgC/L), respectively. $V_{i}$ and $V_{e}$ are the volumes of initial and effluent solutions of AHA from the XAD 8/4 columns (L), respectively, and $W$ is the mass of adsorbent material (mg). 


\subsection{Procedure for Combined XAD 8/4 Resin Isolation with SPE Cartridges}

SPE was performed with an SPE device (Autotrace 280, Dionex, Sunnyvale, CA, USA) for the isolation of DOM using cartridges packed with XAD 8/4 resins. Empty plastic SPE cartridges $(6 \mathrm{~mL}$, Sigma-Aldrich, St. Louis, MO, USA) were filled with a sufficient amount of XAD 8/4 resins (7 g), which prevents exceeding the adsorption capacity of XAD 8/4 resins using a 25-mL glass pipette. The combined XAD 8/4 isolation method with the cartridges was also set in series. The bottom of the cartridge packed with XAD 8 resin was manually connected to the cartridge packed with XAD 4 resin with tubing used in the SPE devices. Thus, the sample water was passed through the XAD 8 cartridge, and then the effluent from the XAD 8 cartridge was passed through the XAD 4 cartridge. This system was further cleaned automatically with DI water, $0.1 \mathrm{M} \mathrm{HCl}$, and $0.1 \mathrm{M} \mathrm{NaOH}$ to remove any impurities using the AutoTrace software program (Dionex, Sunnyvale, CA, USA).

After the cleaning procedure, $600 \mathrm{~mL}$ of samples were passed through the combined XAD 8/4 system using the SPE device (XAD 8 followed by XAD 4), and the effluent solution from the cartridges of XAD 8/4 resins was collected after $200 \mathrm{~mL}$ of water samples had passed through the system. After sample collection, the adsorbed HPO and HPI DOM were automatically eluted from the XAD 8/4 resins using $0.1 \mathrm{M} \mathrm{NaOH}$. The eluates were immediately neutralized using $0.1 \mathrm{HCl}$ to avoid oxidation of DOM at $\mathrm{pH} 7$.

\subsection{Analytical Methods}

The concentration of DOC and total nitrogen (TN) were measured using a total organic carbon analyzer (TOC- $\mathrm{V}_{\mathrm{CPH}}$, Shimadzu, Kyoto, Japan) coupled with a TN analyzer (TNM-1, Shimadzu, Kyoto, Japan). The relative HPO, TPI, and HPI fractions and the carbon mass balance were determined using the DOC concentration of raw samples, the effluent, and the eluate samples from the XAD 8/4 resins by the following equations:

$$
\begin{gathered}
\mathrm{HPO}(\%)=\frac{W_{\text {raw }}-W_{X A D 8, \text { eff }}}{W_{\text {raw }}} \times 100=\frac{W_{X A D 8, \text { elu }}}{W_{\text {raw }}} \times 100 \\
\operatorname{TPI}(\%)=\frac{W_{X A D 8, \text { eff }}-W_{X A D 4, \text { eff }}}{W_{\text {raw }}} \times 100=\frac{W_{X A D 4, \text { elu }}}{W_{\text {raw }}} \times 100 \\
\text { HPI }(\%)=\frac{W_{X A D 4, \text { eff }}}{W_{\text {raw }}} \times 100 \\
\text { Recovery }(\%)=\frac{W_{X A D 8, \text { elu }}+W_{X A D 4, \text { elu }}+W_{X A D 4, \text { eff }}}{W_{\text {raw }}} \times 100 \\
\mathrm{~W}(\mathrm{mgC})=\mathrm{C}\left(\mathrm{mgC} \cdot L^{-1}\right) \times V(m L) \times 10^{-3}
\end{gathered}
$$

where $W_{\text {raw }}, W_{X A D 8, \text { eff }}$, and $W_{X A D 4, \text { eff }}$ are the carbon mass of the raw sample and effluent samples from the XAD 8 and XAD 4 resins (mg), respectively. $W_{X A D 8 \text {, elu }}$ and $W_{X A D 4, ~ e l u}$ are the carbon masses of eluate samples from XAD 8 and XAD 4 resins. $C$ is the carbon concentration of the sample, and $V$ is the volume of the sample water, respectively.

The aromatic content of DOM in terms of UV absorbance at $254 \mathrm{~nm}\left(\mathrm{UVA}_{254}\right)$ was determined by a UV/Vis spectrometer (UV-1601, Shimadzu, Kyoto, Japan) with a 1-cm quartz cell (Hellma, Mülheim, Germany), and specific UV absorbance (SUVA) values were calculated as SUVA (L/mg m) $=\mathrm{UVA}_{254}$ $(/ \mathrm{cm}) / \mathrm{DOC}(\mathrm{mg} / \mathrm{L}) \times 100$. the molecular weight $(\mathrm{MW})$ distributions of DOM were confirmed by high-performance size-exclusion chromatography (eluant composition $=96 \mathrm{mM} \mathrm{NaCl}+2.4 \mathrm{mM} \mathrm{NaH} \mathrm{PO}_{4}$ $+1.6 \mathrm{mM} \mathrm{Na}_{2} \mathrm{HPO}_{4}, \mathrm{pH}=6.8$; flow rate $=0.7 \mathrm{~mL} / \mathrm{min}$ ) system equipped with a Protein-Pak 125 column (Waters, Milford, MA, USA) and UVA and fluorescence detection [17,18]. A Curie-point pyrolyzer (JCI-22, JAI, Chiba, Japan) was used for organic pyrolysis. Approximately $0.1 \mathrm{mg}$ of the freeze-dried eluates from XAD 8/4 resins were prepared in a ferromagnetic foil (Pyrofoil F590, JAI, Chiba, Japan). The pyrolyzed 
fragments of the freeze-dried eluates from XAD 8/4 resins were analyzed using a GC/MS (5975C, Agilent, Santa Clara, CA, USA) equipped with a Curie-point pyrolyzer (JCI-22, JAI, Chiba, Japan). The pyrolysis temperature was $590^{\circ} \mathrm{C}$, and the volatilized compounds were injected into the GC/MS column (DB-5, Agilnet, Santa Clara, CA, USA). The initial oven temperature of the GC/MS was adjusted to $40^{\circ} \mathrm{C}$, and the temperature was steadily increased $\left(7^{\circ} \mathrm{C} / \mathrm{min}\right)$ until the final temperature was $300^{\circ} \mathrm{C}$. A capillary column ( $30 \mathrm{~m} \times 0.25 \mathrm{~mm}$ i.d.) coated with a $0.25 \mu \mathrm{m}$ film of $5 \%$ phenyl methyl siloxane was used. High purity helium gas was used as carrier gas at a flow rate of $1.0 \mathrm{~mL} \mathrm{~min}^{-1}$. The pyrolyzed fragments of the three samples were categorized into six groups based on Bruchet et al.'s work: polysaccharides, amino sugars, proteins, polyhydroxy aromatic (PHA) compounds, lignin, and lipids [19].

\section{Results and Discussion}

\subsection{Comparison of Time for Organic Matter Combined Isolation with XAD 8/4 Resins}

Table 1 shows the procedure time and carbon recovery rates for organic matter isolation by the combined XAD 8/4 isolation method with general columns and with SPE cartridges. XAD 8/4 resin isolation with columns required $779 \mathrm{~min}$ for NOM isolation. A large portion of the total time was for cleaning (365 $\mathrm{min}$ ) because this step used three types of solutions for cleaning resins: $\mathrm{NaOH}, \mathrm{HCl}$, and $\mathrm{DI}$ water solutions. The second-largest time-consuming step was sample loading (300 min), but this time depends on the DOC concentration in a sample. In this experiment, we loaded $600 \mathrm{~mL}$ of each of the samples with various concentrations of DOC. If the sample has a low DOC concentration, the sample loading volume should increase to obtain distinguishable adsorption in each resin. DOM isolation with SPE cartridges showed less time than that for isolation with the columns. It required only a total of $265 \mathrm{~min}$, including $126 \mathrm{~min}$ for cleaning and $100 \mathrm{~min}$ for sample loading. The duration of each step was determined based on the amount of resins in the SPE cartridge. The amount in a SPE cartridge was approximately three times less than that in a column (SPE cartridge: $7 \mathrm{~g}$, columns: $21.5 \mathrm{~g}$ ), and the volume of solution in each step was reduced by one third. Therefore, the XAD isolation method with SPE cartridges was able to reduce about $70 \%$ of the total time and volume of the solution compared to the conventional method. In addition, the isolation method using SPE cartridges improved carbon recovery from $88.9 \%$ to $95.9 \%$. The detailed results relating to DOC adsorption are discussed in Section 3.2.

Table 1. Procedures of DOM isolation using the combined XAD 8/4 resins with columns and with SPE cartridges.

\begin{tabular}{|c|c|c|c|c|c|c|}
\hline \multirow{2}{*}{ Procedure } & \multirow{2}{*}{ Solution } & \multirow{2}{*}{$\begin{array}{c}\text { Flow Rate } \\
\text { (mL/min) }\end{array}$} & \multicolumn{2}{|c|}{ XAD with Columns } & \multicolumn{2}{|c|}{ XAD with SPE } \\
\hline & & & Amount (mL) & Duration (min) & Amount (mL) & Duration (min) \\
\hline \multirow{13}{*}{ Clean } & DI water & 2 & 250 & 125 & 83 & 42 \\
\hline & $\begin{array}{c}0.1 \mathrm{~N} \\
\mathrm{NaOH}\end{array}$ & 2 & 40 & 20 & 13 & 7 \\
\hline & DI water & 2 & 40 & 20 & 13 & 7 \\
\hline & $0.1 \mathrm{~N} \mathrm{HCl}$ & 2 & 40 & 20 & 13 & 7 \\
\hline & DI water & 2 & 40 & 20 & 13 & 7 \\
\hline & $\begin{array}{c}0.1 \mathrm{~N} \\
\mathrm{NaOH}\end{array}$ & 2 & 40 & 20 & 13 & 7 \\
\hline & DI water & 2 & 40 & 20 & 13 & 7 \\
\hline & $0.1 \mathrm{~N} \mathrm{HCl}$ & 2 & 40 & 20 & 13 & 7 \\
\hline & DI water & 2 & 40 & 20 & 13 & 7 \\
\hline & $\begin{array}{c}0.1 \mathrm{~N} \\
\mathrm{NaOH}\end{array}$ & 2 & 40 & 20 & 13 & 7 \\
\hline & DI water & 2 & 40 & 20 & 13 & 7 \\
\hline & $0.1 \mathrm{~N} \mathrm{HCl}$ & 2 & 40 & 20 & 13 & 7 \\
\hline & DI water & 2 & 40 & 20 & 13 & 7 \\
\hline Acidify & $0.1 \mathrm{~N} \mathrm{HCl}$ & 2 & 40 & 20 & 13 & 7 \\
\hline Load & Sample & 2 & 600 & 300 & 200 & 100 \\
\hline Wash & DI water & 2 & 8 & 4 & 3 & 2 \\
\hline
\end{tabular}


Table 1. Cont

\begin{tabular}{|c|c|c|c|c|c|c|}
\hline \multirow{2}{*}{ Procedure } & \multirow{2}{*}{ Solution } & \multirow{2}{*}{$\begin{array}{c}\text { Flow Rate } \\
(\mathrm{mL} / \mathrm{min})\end{array}$} & \multicolumn{2}{|c|}{ XAD with Columns } & \multicolumn{2}{|c|}{ XAD with SPE } \\
\hline & & & Amount (mL) & Duration (min) & Amount (mL) & Duration (min) \\
\hline \multirow{3}{*}{ Elute } & $\begin{array}{c}0.1 \mathrm{~N} \\
\mathrm{NaOH}\end{array}$ & 1 & 40 & 40 & 13 & 13 \\
\hline & DI & 1 & 20 & 20 & 7 & 7 \\
\hline & $0.1 \mathrm{~N} \mathrm{HCl}$ & 1 & 30 & 30 & 10 & 10 \\
\hline Total & & & 1468 & 779 & 485 & 265 \\
\hline Recovery (\%) & & & 88.9 & & & 5.9 \\
\hline
\end{tabular}

\subsection{Adsorption Capacity $\left(q_{e}\right)$ of Combined XAD 8/4 Resins for $A H A$}

The kinetic profiles of the adsorption of AHA on the XAD 8/4 resins are shown in Figure 2. The adsorption capacities of both resins increased with time and reached the saturation condition. The XAD 8 resin adsorbed a higher amount of AHA than did the XAD 4 resin, which is in good agreement with previous studies regarding the adsorption of humic substances with the same resins $[8,20]$. The chemical structure of the XAD 8 resin is that of an acrylic non-aromatic ester, while that of XAD 4 is a styrene divinylbenzene copolymer resin containing aromatic and very HPO characteristics. Since the adsorption capacity of XAD resins is affected by chemical composition, it caused a difference in adsorption capacities between XAD 8 and XAD 4 resins [8]. In addition, the large pore size of the XAD 8 resin $(>25 \mathrm{~nm})$ induces rapid adsorption by diffusion of macromolecules into the resin matrix compared with that of the XAD 4 resin $(<5 \mathrm{~nm})$ [11]. Thus, a large amount of AHA, which is a HPO macromolecule, could be adsorbed by the XAD 8 resin.

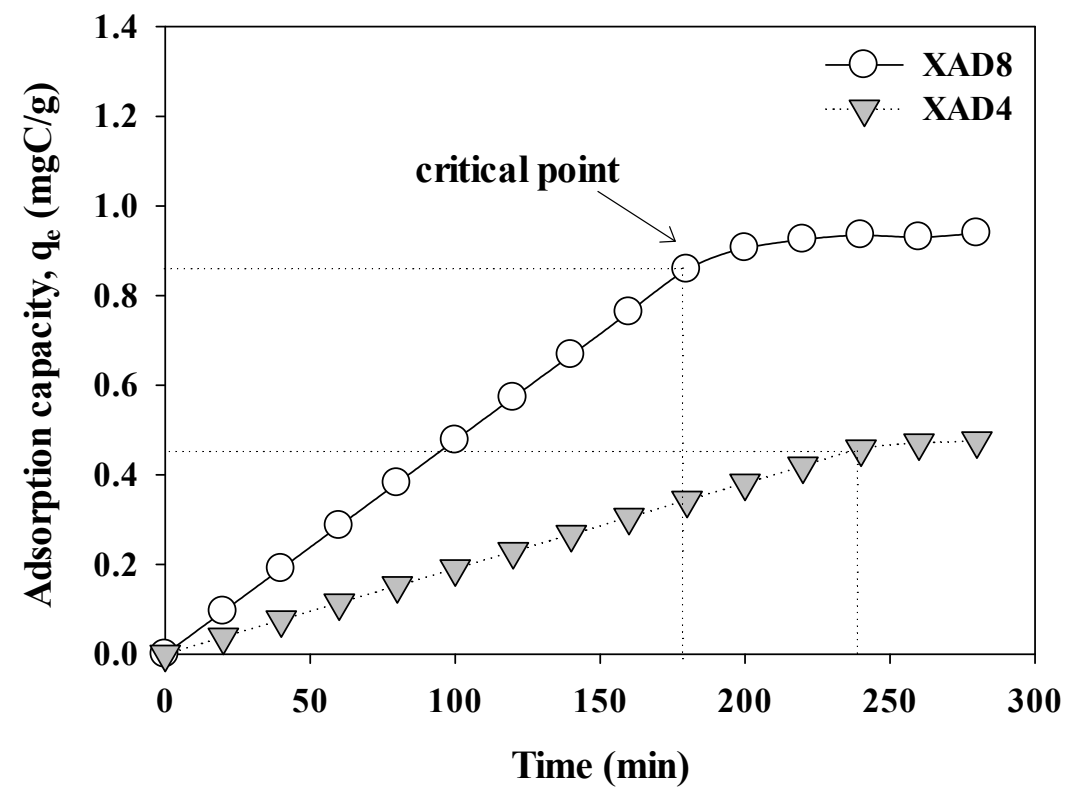

Figure 2. Adsorption capacity $\left(q_{e}\right)$ of XAD 8/4 resins for Aldrich humic acid (AHA).

The adsorption capacity is especially important for the combined XAD 8/4 isolation method because the HPO fraction of DOM that exceeds the adsorption capacity of the XAD 8 resin adsorbs onto the XAD 4 resin; it then interferes with an accurate assessment of the HPO fraction of DOM. The critical point of the adsorption capacity indicates enough resin for packing in the SPE cartridges. The obtained value from the experiment provides practical information that enables finding an optimal amount of resins for adsorption. In Figure 2, XAD 8 showed $0.86 \mathrm{mgC} / \mathrm{g}$ of maximum capability, and XAD 4 had $0.46 \mathrm{mgC} / \mathrm{g}$ for $10 \mathrm{mgC} / \mathrm{L}$ of AHA adsorption. According to these results, we packed the SPE cartridge using $7 \mathrm{~g}$ of XAD 8/4 resins. The amount of resin packed in columns versus SPE cartridges was reduced by approximately $14 \mathrm{~g}$ for the latter in the adsorption experiment. 
3.3. Relative Fraction of AHA and Mass Balance Determined by Combined XAD 8/4 Isolation with Columns and SPE Cartridges

AHA was fractionated into three fractions by two isolation methods (with columns and SPE cartridges): HPO, TPI, and HPI fractions (Figure 3). The percentage of each fraction of AHA from both methods showed similar values. The column test fractionated AHA into $60 \% \mathrm{HPO}, 14 \%$ TPI, and $24 \%$ HPI organic matter. The fractions from the SPE cartridge showed 57\% HPO, 16\% TPI, and 26\% HPI organic matter.

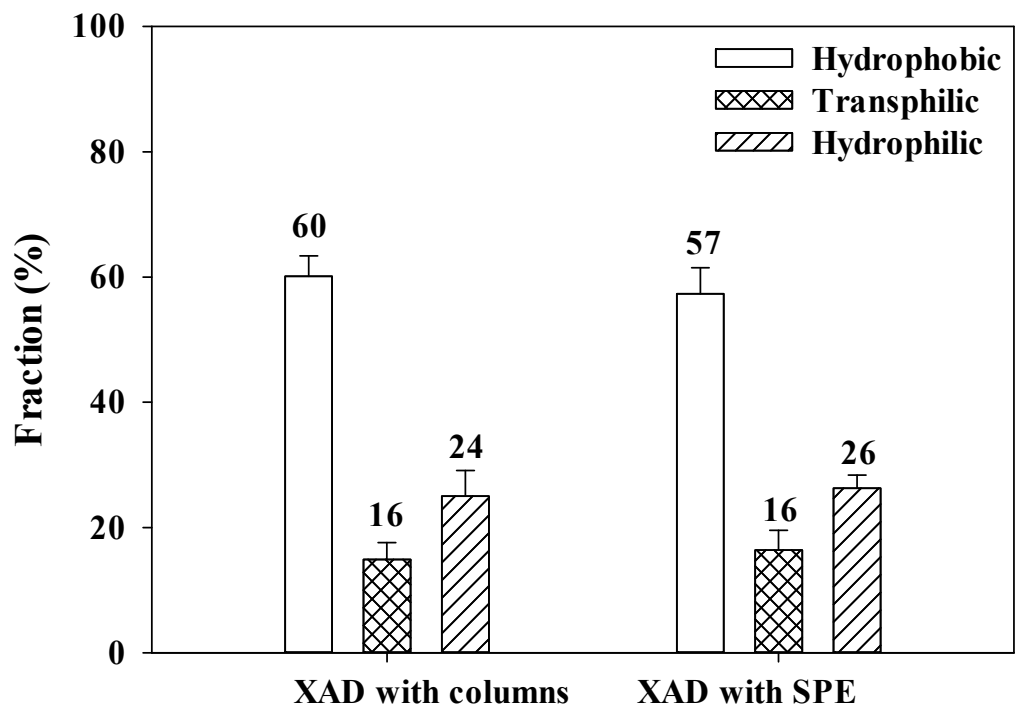

Figure 3. Relative hydrophobicity of AHA determined by combined XAD8/4 isolation with columns and SPE cartridges.

However, when comparing the mass balance results between the two experiments, the isolation method using the SPE devices showed a higher carbon recovery than did that using columns (Table 2). The total carbon mass of each experiment was calculated by the summation of the carbon mass in the fractions. The recovery rate from isolation with the SPE devices was 95.9\%, while that with columns was $88.9 \%$. We suggest possible reasons for the higher recovery value of the isolation method with the SPE device. The first reason is the difference in the material properties of the tube for sample loading. The isolation method with columns used a flexible silicon rubber tube, which can absorb lipophilic compounds [21], while the method with the SPE devices used a relatively nonflexible tube coated internally with Teflon. Secondly, the column had headspace volume due to compaction of the resins after sample loading, while the SPE cartridge did not exhibit this space. Thus, less water might have been loaded into the column than into the SPE cartridge during the same time period.

Table 2. Carbon mass balance of AHA through combined XAD 8/4 isolation with columns and with SPE cartridges.

\begin{tabular}{cccc}
\hline & & XAD with Columns & XAD with SPE \\
\hline \multirow{3}{*}{ Carbon mass (mgC) } & Raw AHA & $5.05 \pm 0$ & $5.05 \pm 0$ \\
& XAD 8 isolate & $2.65 \pm 0.02$ & $2.74 \pm 0.02$ \\
& XAD 4 isolate & $0.63 \pm 0.01$ & $0.79 \pm 0.01$ \\
\hline & XAD 4 effluent & $1.21 \pm 0.01$ & $1.31 \pm 0.01$ \\
& Total & $4.49 \pm 0.04$ & $4.84 \pm 0.04$ \\
\hline Recovery (\%) & & $88.9 \pm 0.8$ & $95.9 \pm 0.6$ \\
\hline
\end{tabular}




\subsection{Physicochemical Properties of Isolated AHA by Combined XAD 8/4 with Columns and with SPE Cartridges}

Changes in the MW distribution of the AHA solution through combined XAD 8/4 isolation with columns and with SPE cartridges were measured in terms of aromatic and protein-like substances (Figure 4). The AHA solution contained aromatic substances, which are detected by UV absorbance at $254 \mathrm{~nm}$, with MW ranges from 388 to $1883 \mathrm{Da}$. The effluent solution passed through the XAD 8 resin in the column, and the SPE cartridge had smaller MW ranges from ca. 390 to ca. 1021 Da owing to adsorption of the resin. Since most of the HPO organic matter is adsorbed on the XAD 8 resin, the amount of DOM in the effluent from the XAD 8 resin is smaller than for the AHA solution, resulting in the lower UV response at $254 \mathrm{~nm}$. However, the effluent from the XAD 4 resin with the columns and SPE cartridge showed almost the same MW distribution as with the XAD 8 effluent samples. The XAD 4 resin was designed to absorb a large proportion of lower-molecular-weight organic matter because the resin is HPO and has a large specific surface area $[8,11]$. The results showed that the chromatogram of the effluent from the XAD 4 resin is not significantly different than the effluent from the XAD 8 resin. This is because most of the AHA HPO organic matter with a SUVA value of $10.55\left(\mathrm{~L} \mathrm{mg}^{-1} \mathrm{~m}^{-1}\right)$ [22] adsorbs on the XAD 8 resin. After the sorption of the XAD 8 resin, the XAD 4 resin could absorb only a small portion of the AHA.

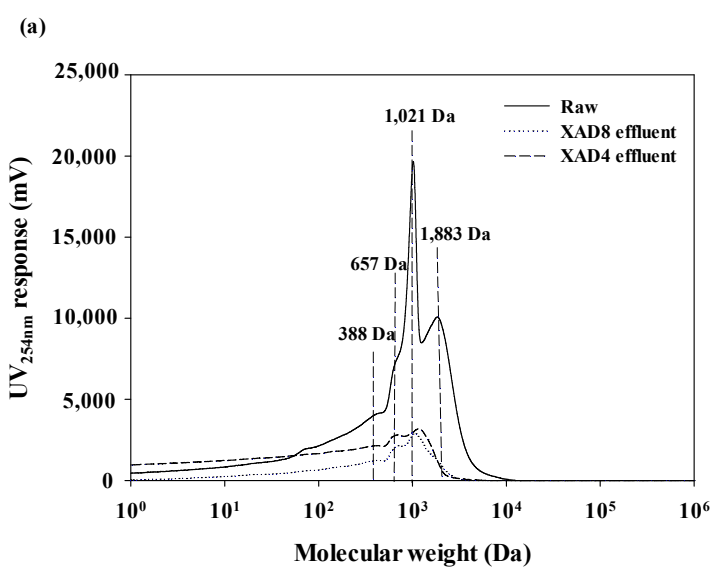

(b)

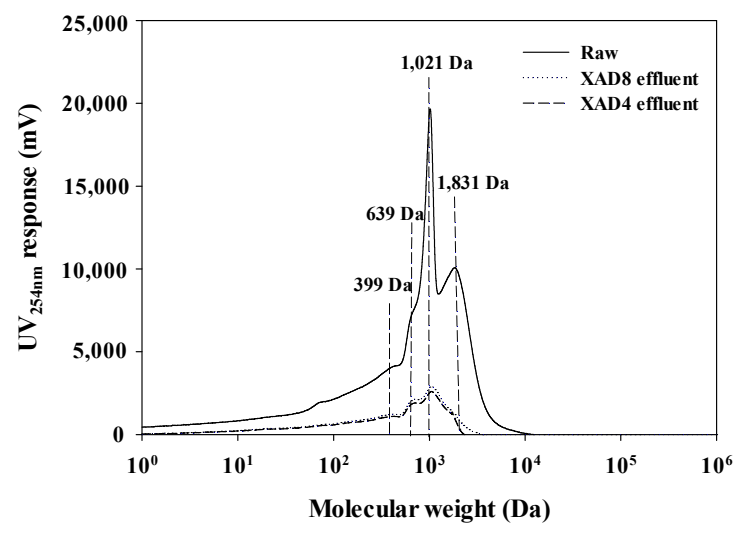

Figure 4. Cont. 
(c)

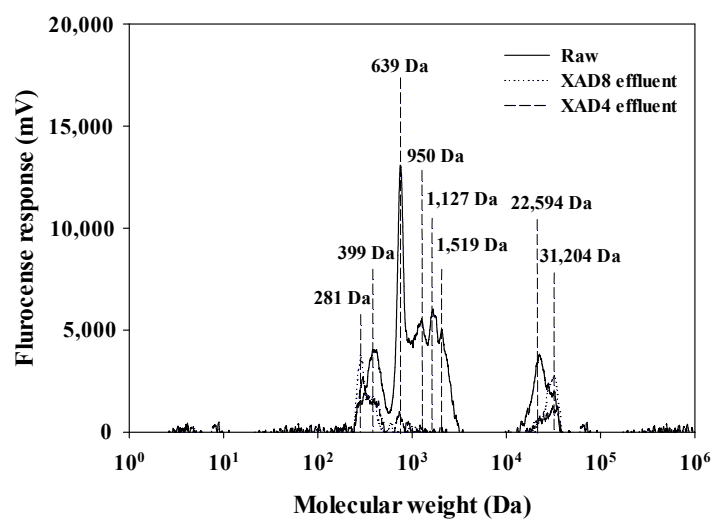

(d)

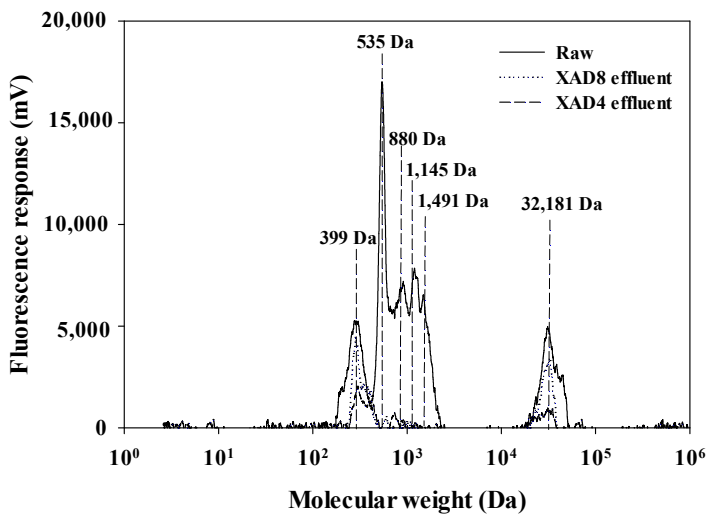

Figure 4. Changes in the molecular weight (MW) distribution of AHA through XAD 8 and 4 resins with $(\mathbf{a}, \mathbf{b})$ columns and $(\mathbf{c}, \mathbf{d})$ solide-phase extraction (SPE) devices: $(\mathbf{a}, \mathbf{c})$ aromatic substance; $(\mathbf{b}, \mathbf{d})$ protein-like substance.

The results of fluorescence absorbance of the samples showed the same pattern as that of UV absorbance (Figure 4c,d). The AHA solution also contained protein-like substances, which are detected by fluorescence absorbance, with MW ranges from 281 to 32,181 Da. The effluent solution passed through the XAD 8 resin in the column, and the SPE cartridge had smaller MW ranges from ca. 639 to ca. 1519 Da owing to adsorption of the resin. Since most of the HPO organic matter is adsorbed on the XAD 8 resin, the amount of DOM in the effluent from the XAD 8 resin is smaller than for the AHA solution, resulting in the lower fluorescence response. Although the effluent from the XAD 4 resin with the columns and SPE cartridge showed almost the same MW distribution for the XAD 8 effluent sample, the amount of DOM in the effluent, whose MW ranges from ca. 22,594 to ca. 31,000, was significantly reduced when passed through the XAD 4 resin. This indicates that protein-like substances with high MWs can be adsorbed more onto the XAD 4 resin than onto the XAD 8 resin.

Moreover, there was no significant difference in the changes of the MW distribution of the AHA through the XAD 8/4 resins between the two methods. This also indicates that the physicochemical property of the effluent from the SPE cartridges packed with the XAD 8/4 resins is the same as that from the general columns.

Tests of the biopolymer compositions of DOM adsorbed onto XAD 8/4 resins from the columns and SPE cartridges were conducted (Figure 5). AHA contained lignin, polysaccharides, protein, and polyhydroxy aromatic (PHA) fragments. These results were similar to those from previous research that reported that pyrolysis products of AHA included furans, pyrroles, phenols, benzenes, and alkanes, which are building blocks of biopolymers [23-25]. Since XAD 8 adsorbed more HPO substances than did XAD 4, In addition, XAD 4 also showed an order similar to the result of XAD 8 for the portion of adsorbed biopolymer (PHA > PS > protein, no lignin portion), even though the 
amount of adsorbed organic matter on XAD 4 was smaller than the amount of the adsorbed organic matter onto XAD 8 (Table 2). This indicates that the eluates from XAD 8/4 resins for AHA may have similar chemical compositions, although the functionalities of the eluates from XAD $8 / 4$ of the humic substances are different [26]. In addition, it was observed that the amount of the protein portion adsorbed onto XAD 4 is higher than the amount of the protein portion adsorbed onto XAD 8, which is in good agreement with the results of the MW distribution for the protein-like substance. Thus, it can be postulated that protein-like substances with high MWs can be more easily adsorbed onto XAD 4 .

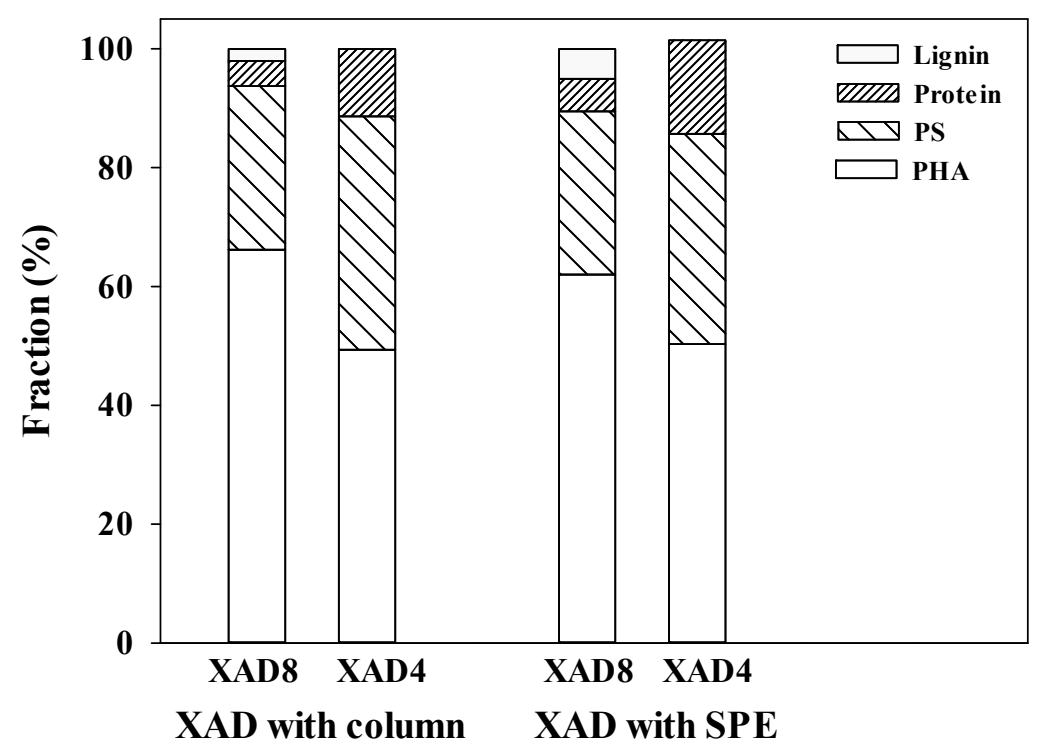

Figure 5. Biopolymer composition of dissolved organic matter (DOM) adsorbed onto XAD 8 and XAD 4 with columns and with SPE devices. (PHA: polyhydroxy aromatic, PS: Polysaccharides).

Moreover, the results showed that there was no significant difference in adsorption of DOM between the two methods. They had the same order relative to the portion of each biopolymer in the XAD 8/4 resins. The combined XAD 8/4 isolation method with SPE cartridges was verified when comparing the biopolymer composition of eluates from the XAD $8 / 4$ resins with that of the column method.

\subsection{Comparison of NOM Fractionation with Environmental Samples by the XAD 8/4 Resins with Columns and with SPE Cartridges}

To validate the practical applications of the developed method, NOM isolation was conducted using three different types of NOMs: MW-NOM, HR-NOM, and SR-NOM. Each sample was analyzed in terms of $\mathrm{pH}, \mathrm{DOC}, \mathrm{UV}_{254}$ absorbance, SUVA, TN, and conductivity (Table 3). $\mathrm{pH}$ values of all samples were in the typical natural water range from 6 to 8 [27]. SR-NOM was dissolved with a DOC concentration of $10 \mathrm{mgC} / \mathrm{L}$. The DOC concentrations of MW-NOM and HR-NOM were 7.6 and $2.1 \mathrm{mgC} / \mathrm{L}$, respectively. SR-NOM had the highest SUVA value (4.3 L/mg-m) compared to the other samples (MW-NOM: $2.8 \mathrm{~L} / \mathrm{mg}-\mathrm{m}$ and HR-NOM: $1.7 \mathrm{~L} / \mathrm{mg}-\mathrm{m}$ ). However, the conductivity and TN values of HR-NOM were the highest among the samples. The difference in the DOC and conductivity between the MW-NOM and HR-NOM derived from the environmental conditions of the samples. MW-NOM was taken from an isolated wetland located at the top of a mountain. Since this site maintained its water level only by rainfall, the conductivity was low, and the DOC concentration was higher than that of river water. However, because the river water sample containing HR-NOM passes through Seoul in Korea, it could contain large amounts of ions from various sources, resulting in high conductivity of the sample. 
Table 3. Water characteristics of various types of natural organic matter.

\begin{tabular}{cccc}
\hline & Muryeongari Wetland (MW-NOM) & Han River (HR-NOM) & Suwannee River (SR-NOM) \\
\hline $\mathrm{pH}$ & 6.5 & 6.8 & 7.3 \\
$\mathrm{DOC}\left(\mathrm{mg}_{-} \mathrm{C} \mathrm{L}^{-1}\right)$ & $7.6 \pm 0.5$ & $2.1 \pm 0.3$ & $10.1 \pm 0.2$ \\
$\mathrm{UV}_{254 \mathrm{~nm}}$ & $0.2123 \pm 0.002$ & $0.0358 \pm 0.001$ & $0.4341 \pm 0.001$ \\
SUVA $\left(\mathrm{L} / \mathrm{mg}^{-1}\right)$ & $2.8 \pm 0.4$ & $1.7 \pm 0.3$ & $4.3 \pm 0.5$ \\
$\mathrm{TN}\left(\mathrm{mg}-\mathrm{N} \mathrm{L}^{-1}\right)$ & $0.4 \pm 0.1$ & $4.6 \pm 0.3$ & $0.2 \pm 0.1$ \\
Conductivity $\left(\mathrm{\mu} \mathrm{cm}^{-1}\right)$ & $42.9 \pm 0.5$ & $321.0 \pm 2.4$ & $12.1 \pm 1.6$ \\
\hline
\end{tabular}

The samples were fractionated using the XAD 8/4 resins with the columns and with the SPE cartridges (Figure 6). The percentages of fractions in each sample were very similar in the samples when comparing the experimental results for the column and for the SPE cartridge. Both experimental results showed that MW-NOM was fractionated into ca. $62 \% \mathrm{HPO}$, ca. $10 \% \mathrm{TPI}$, and ca. $28 \% \mathrm{HPI}$ organic matter. HR-NOM had a large portion of HPI organic matter $(60 \%)$ and contained $23 \% \mathrm{HPO}$ and $6 \%$ TPI organic matter. The results showed that the method with the SPE cartridge packed with XAD 8/4 resins can accurately fractionate various NOMs with different hydrophobicity and conductivity values.

(a)

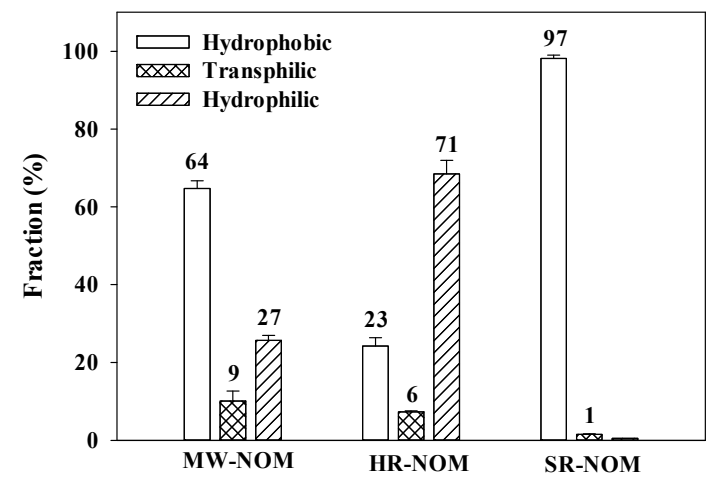

(b)

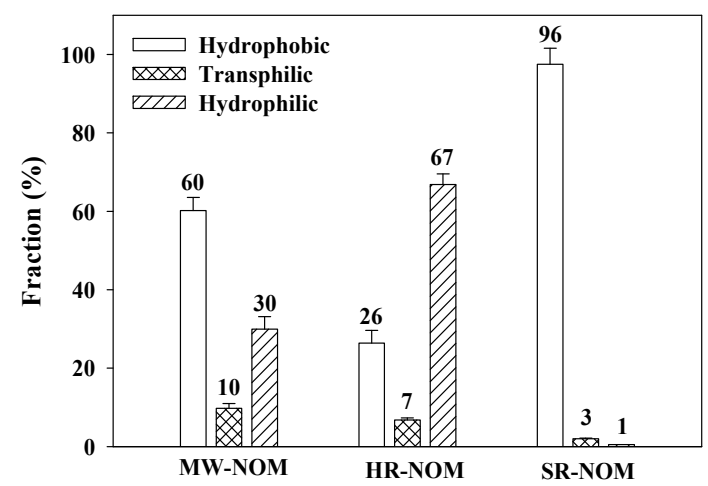

Figure 6. Relative polarity of various types of natural organic matter determined by XAD (a) with columns and (b) with SPE cartridges.

\section{Conclusions}

An isolation method for organic matter using SPE cartridges packed with XAD 8/4 resins was developed in comparison with an isolation method using general columns filled with XAD 8/4 resins in this study. The HPO, TPI, and HPI fractions of the four different organic matter types considered (AHA, MW-NOM, HR-NOM, and SR-NOM) by both isolation methods showed similar values. The changes in the MW distribution of the effluent solution from the XAD 8/4 resin using both isolation methods also 
showed the same pattern. In addition, the difference between the methods in terms of the biopolymer composition of eluates from XAD 8/4 resins was not significant. However, a higher carbon recovery rate of the isolation method using the cartridge packed with XAD resins was found than in the isolation method with general columns (with columns: $88.9 \%$, with SPE cartridges: $95.9 \%$ ). In addition, isolation using the SPE cartridges was much faster than that using general columns. These results suggested that the isolation method using an SPE device equipped with cartridges packed with XAD 8/4 resins is not only accurate for various organic matter types but is also very effective and practical for reducing required time and labor with high sample recovery.

Author Contributions: H.R. developed the XAD with the SPE system and analyzed the water characteristics. K.C. collected water samples. J.P. and J.C. designed the experiments and drew the conclusions.

Funding: This research was funded by the National Research Foundation of Korea (NRF) Grant funded by the Korean Government (MSIP) (No. NRF-2015R1A5A7037825) and by the Korea Institute of Energy Technology Evaluation and Planning (KETEP) through "Human Resources Program in Energy Technology" (No. 20164030201010/No. 20184030202250) funded by the Ministry of Trade, Industry and Energy, Republic of Korea.

Acknowledgments: This research was supported by the National Research Foundation of Korea (NRF) Grant funded by the Korean Government (MSIP) (No. NRF-2015R1A5A7037825) and by the Korea Institute of Energy Technology Evaluation and Planning (KETEP) through "Human Resources Program in Energy Technology" (No. 20164030201010/No. 20184030202250) funded by the Ministry of Trade, Industry and Energy, Republic of Korea.

Conflicts of Interest: The authors declare no conflict of interest.

\section{References}

1. Dietrich, A.M. Aesthetic issues for drinking water. J. Water Health 2006, 4, 11-16. [CrossRef] [PubMed]

2. Nyström, M.; Ruohomäki, K.; Kaipia, L. Humic acid as a fouling agent in filtration. Desalination 1996, 106, 79-87. [CrossRef]

3. Yuan, W.; Zydney, A.L. Effects of solution environment on humic acid fouling during microfiltration. Desalination 1999, 122, 63-76. [CrossRef]

4. Daignault, S.A.; Noot, D.K.; Williams, D.T.; Huck, P.M. A review of the use of XAD resins to concentrate organic compounds in water. Water Res. 1988, 22, 803-813. [CrossRef]

5. Mantoura, R.F.C.; Riley, J.P. The analytical concentration of humic substances from natural waters. Anal. Chim. Acta 1975, 76, 97-106. [CrossRef]

6. Thurman, E.M. Trace Compounds. In Organic Geochemistry of Natural Waters; Springer: Berlin, Germany, 1985; pp. 243-271.

7. Leenheer, J.A. Comprehensive approach to preparative isolation and fractionation of dissolved organic carbon from natural waters and wastewaters. Environ. Sci. Technol. 1981, 15, 578-587. [CrossRef] [PubMed]

8. Aiken, G.R.; Thurman, E.M.; Malcolm, R.L.; Walton, H.F. Comparison of XAD macroporous resins for the concentration of fulvic acid from aqueous solution. Anal. Chem. 1979, 51, 1799-1803. [CrossRef]

9. Thurman, E.M.; Malcolm, R.L.; Aiken, G.R. Prediction of capacity factors for aqueous organic solutes adsorbed on a porous acrylic resin. Anal. Chem. 1978, 50, 775-779. [CrossRef]

10. Aiken, G.R.; McKnight, D.M.; Thorn, K.A.; Thurman, E.M. Isolation of hydrophilic organic acids from water using nonionic macroporous resins. Org. Geochem. 1992, 18, 567-573. [CrossRef]

11. Malcolm, R.L.; MacCarthy, P. Quantitative evaluation of XAD-8 and XAD-4 resins used in tandem for removing organic solutes from water. Environ. Int. 1992, 18, 597-607. [CrossRef]

12. Poole, C.F. New trends in solid-phase extraction. TrAC Trends Anal. Chem. 2003, 22, 362-373. [CrossRef]

13. Mallet, A.I. Solid-phase extraction: Principles and practice E. M THURMAN and M. S MILLS: vol 147 in series chemical analysis, ed. J. D. Winefordner, John Wiley and Sons, New York, 1998 ISBN 047161422 X Price £50. Rapid Commun. Mass Spectrom. 1998, 12, 988. [CrossRef]

14. Rendle, D. Analytical Solid-Phase Extraction, by J.S. Fritz, Wiley-VCH, New York, 1999, xiii+209 pp, ISBN 0-471-24667-0; £41.95. Talanta 2000, 51, 1235. [CrossRef]

15. Simpson, N. Solid-Phase Extraction; CRC Press: Boca Raton, FL, USA, 2000; ISBN 9780824700218.

16. Pawliszyn, J. Chapter 9 Unified theory of extraction. Sampl. Sample Prep. Field Lab. 2002, 37, 253-278. 
17. Her, N.; Amy, G.; McKnight, D.; Sohn, J.; Yoon, Y. Characterization of DOM as a function of MW by fluorescence EEM and HPLC-SEC using UVA, DOC, and fluorescence detection. Water Res. 2003, 37, 4295-4303. [CrossRef]

18. Her, N.; Amy, G.; Foss, D.; Cho, J.; Yoon, Y.; Kosenka, P. Optimization of Method for Detecting and Characterizing NOM by HPLC-Size Exclusion Chromatography with UV and On-Line DOC Detection. Environ. Sci. Technol. 2002, 36, 1069-1076. [CrossRef] [PubMed]

19. Bruchet, A.; Rousseau, C.; Mallevialle, J. Pyrolysis-GC-MS for Investigating High-Molecular-Weight THM Precursors and Other Refractory Organics. J. Am. Water Works Assoc. 1990, 82, 66-74. [CrossRef]

20. Rodríguez, J.; Castrillón, L.; Marañón, E.; Sastre, H.; Fernández, E. Removal of non-biodegradable organic matter from landfill leachates by adsorption. Water Res. 2004, 38, 3297-3303. [CrossRef]

21. Reinsberg, J.; Ackermann, D.; van der Ven, H. Pitfalls in assessment of progesterone production by granulosa cells cultured in contact with silicone rubber or paraffin oil. Arch. Gynecol. Obstet. 2003, 270, 174-178. [CrossRef]

22. Valencia, S.; Marín, J.M.; Restrepo, G.; Frimmel, F.H. Application of excitation-emission fluorescence matrices and UV/Vis absorption to monitoring the photocatalytic degradation of commercial humic acid. Sci. Total Environ. 2013, 442, 207-214. [CrossRef]

23. Fuentes, M.; Baigorri, R.; González-Vila, F.J.; González-Gaitano, G.; García-Mina, J.M. Pyrolysis-Gas Chromatography/Mass Spectrometry Identification of Distinctive Structures Providing Humic Character to Organic Materials. J. Environ. Qual. 2010, 39, 1486. [CrossRef] [PubMed]

24. Leenheer, J.A.; Croué, J.-P. Peer Reviewed: Characterizing Aquatic Dissolved Organic Matter. Environ. Sci. Technol. 2003, 37, 18A-26A. [CrossRef] [PubMed]

25. Wilson, M.A.; Philp, R.P.; Gillam, A.H.; Gilbert, T.D.; Tate, K.R. Comparison of the structures of humic substances from aquatic and terrestrial sources by pyrolysis gas chromatography-mass spectrometry. Geochim. Cosmochim. Acta 1983, 47, 497-502. [CrossRef]

26. Cho, J.; Amy, G.; Pellegrino, J. Membrane filtration of natural organic matter: Factors and mechanisms affecting rejection and flux decline with charged ultrafiltration (UF) membrane. J. Memb. Sci. 2000, 164, 89-110. [CrossRef]

27. Ferry, J.D.; Carritt, D.E. Action of Antifouling Paints. Ind. Eng. Chem. 1946, 38, 612-617. [CrossRef]

(C) 2019 by the authors. Licensee MDPI, Basel, Switzerland. This article is an open access article distributed under the terms and conditions of the Creative Commons Attribution (CC BY) license (http:/ / creativecommons.org/licenses/by/4.0/). 